\begin{tabular}{|c|c|c|}
\hline & $\begin{array}{l}\text { European Association for the } \\
\text { Development of Renewable Energies, Environment } \\
\text { and Power Quality (EA4EPQ) }\end{array}$ & $\begin{array}{c}\text { International Conference on Renewable Energies and Power Quality } \\
\text { (ICREPQ'12) } \\
\text { Santiago de Compostela (Spain), 28th to 30th March, } 2012\end{array}$ \\
\hline
\end{tabular}

\title{
Fuzzy Logic Controller Based Perturb and Observe Maximum Power Point Tracking
}

\author{
A. Al Nabulsi, R. Dhaouadi \\ College of Engineering \\ American University of Sharjah \\ P.O. Box 26666, Sharjah, United Arab Emirates \\ E-mail: b00016969@aus.edu, rdhaouadi@aus.edu
}

\begin{abstract}
This paper presents a fuzzy logic controller (FLC) based technique to design an adaptive perturb and observe $(\mathrm{P} \& \mathrm{O})$ maximum power point tracking (MPPT) controller. The objective is to improve the efficiency of a standalone solar energy system consisting of a photovoltaic (PV) panel and a DC/DC buck converter connected to a variable load. The proposed FLC based technique is implemented on a TMS320F28335 DSP board and compared to the conventional $\mathrm{P} \& \mathrm{O}$ technique. The performance of the proposed system is validated through outdoor experiments with a 150-Watt PV system.
\end{abstract}

\section{Key words}

Fuzzy logic, MPPT, P\&O, PV panel, buck converter

\section{Introduction}

Significant progress has been made over the last few years in the research and development of renewable energy systems such as wind, sea wave and solar energy systems. Among these resources, solar energy is considered nowadays as one of the most reliable, daily available, and environment friendly renewable energy source [1], [2].

However, solar energy systems generally suffer from their low efficiencies and high costs [3]. In order to overcome these drawbacks, maximum power should be extracted from the PV panel using MPPT techniques to optimize the efficiency of overall PV system. MPPT is a real-time control scheme applied to the PV power converter in order to extract the maximum power possible from the PV panel. The MPPT working principle is based on the maximum power transfer theory. The power delivered from the source to the load is maximized when the input resistance seen by the source matches the source resistance. Therefore, in order to transfer maximum power from the panel to the load the internal resistance of the panel has to match the resistance seen by the PV panel. For a fixed load, the equivalent resistance seen by the panel can be adjusted by changing the power converter duty cycle [4]. The literature is rich with various MPPT techniques based on different topologies and with varying complexity, cost, and overall produced efficiency. The Hill Climbing (HC) and the Perturb and Observe (P\&O) are the most known and commercially used techniques [5]-[8]. Other modified methods such as the incremental Conductance (INC) technique [9], the neural network (NN) technique [10], and fuzzy logic controller technique [10], [11] have been also reported to improve the performance of these techniques.

In HC-MPPT technique, the duty cycle is directly incremented or decremented in fixed steps depending on the panel voltage and power values until the maximum power point (MPP) is reached. The $\mathrm{P} \& \mathrm{O}$ technique shares the same HC concept of operation, but with an additional PI control loop. In the $\mathrm{P} \& \mathrm{O}$, the converter input reference voltage is the perturbed variable and the duty cycle is computed through an additional PI control loop. The additional control loop results in an increase in the P\&O efficiency, as the system demonstrates a faster dynamic performance and better-regulated PV output voltage compared to $\mathrm{HC}$.

The $\mathrm{P} \& \mathrm{O}$ method is commonly used because of its simplicity and ease of implementation [5]-[8]. Furthermore, $\mathrm{P} \& \mathrm{O}$ (with a small step size) in nominal conditions can have MPPT efficiencies mostly the same like other complex techniques, and still easier implementation [6]. However, the drawback of this technique is that the operating point of the PV array oscillates around the MPP. Therefore, the power loss may increase. Furthermore, when the sun insolation changes rapidly, the P\&O method probably fails to track the MPP. Another possible disadvantage is that the MPPT may not be able to locate the MPP as the amount of sunlight decreases, because the PV curve flattens out [5]. 
In order to overcome these drawbacks and improve the $\mathrm{P} \& \mathrm{O}$ response, many techniques are suggested and investigated in the literature such as, the introduction of three-point weight comparison $\mathrm{P} \& \mathrm{O}$ algorithm [7] and the use of modified adaptive techniques [8].

This paper proposes a new fuzzy based MPPT technique to adaptively change the $\mathrm{P} \& \mathrm{O}$ perturbation voltage step-size depending on the PV system operating point and the old step-size. The proposed control scheme achieves stable operation in the entire region of the PV panel and eliminates therefore the resulting oscillations around the maximum power operating point. The small signal analysis of the power converter model is presented along with a Lyapunov based stability analysis of the PV system.

\section{PV System Model}

The proposed standalone photovoltaic (PV) system consists of three main blocks: PV panel, power converter, and MPPT controller. The following sections will describe the modeling of the PV panel and power converter.

\section{A. PV Panel Model}

The PV model represents the solar cell in its simplest form as a PN junction followed by a series resistance as shown in Fig. 1 [12]. The PV system equivalent circuit is described by the following equations:

$$
\begin{gathered}
V_{\text {cell }}=V_{D}-I_{\text {cell }} R_{s} \\
I_{\text {cell }}=I_{p h}-I_{D}=I_{p h}-I_{o}\left(e^{K_{P V}\left(V_{\text {panel }}+I_{\text {cell }} R_{s}\right)}-1\right)
\end{gathered}
$$

where $V_{\text {cell }}$ is the PV cell terminal voltage, $V_{D}$ is the diode voltage, $I_{\text {cell }}$ is the PV cell terminal current, $I_{D}$ is the diode current. $K_{P V}=\frac{q}{p K T}, \quad q=1.6 \times 10^{-19} \mathrm{C}$ (electron charge), $\quad K=1.3805 \times 10^{-23} \mathrm{~J} / \mathrm{K}$ (Boltzmann's constant), $\mathrm{T}$ is the cell temperature, and $\mathrm{p}=1.3$ is the ideal $\mathrm{p}-\mathrm{n}$ junction characteristic factor for monocrystalline solar cells. $I_{o}$ is the saturation current in diode reverse-biased direction and $R_{s}$ is the panel series resistance:

$$
I_{o}=I_{r r}\left(\frac{T}{T_{r}}\right)^{3} e^{\left(\frac{q V_{g}\left(\frac{1}{T_{r}}-\frac{1}{T}\right)}{p K}\right)}
$$

where $I_{r r}$ is the reverse saturation current at the reference temperature $T_{r} \cdot V_{g}$ is the band-gap voltage of the semiconductor making up the cell, which equals $1.12 \mathrm{eV}$ for monocrystalline Si cells, and $I_{p h}$ is the Photocurrent

$$
I_{p h}=\left(I_{s c}+K_{I}\left(T-T_{r}\right)\right) \frac{\lambda}{100}
$$

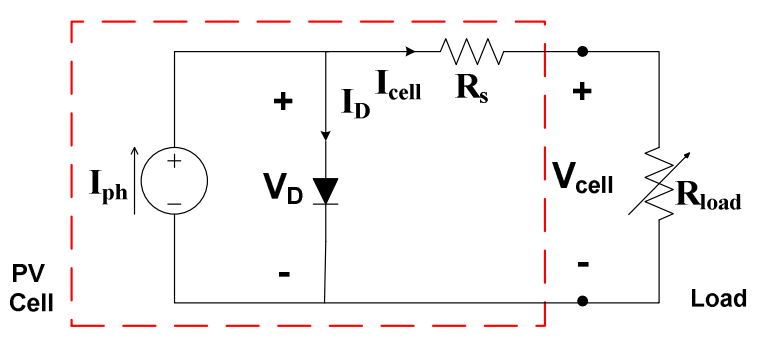

Fig. 1. PV system circuit model.

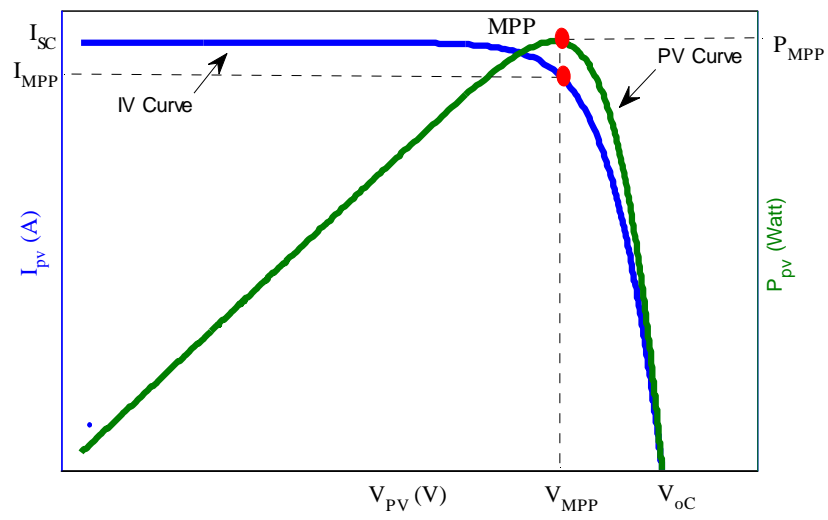

Fig. 2. PV panel characteristics

$I_{s c}$ is the short-circuit cell current at reference temperature and insolation, $K_{I}$ in $(\mathrm{mA} / \mathrm{K})$ is the short circuit current temperature coefficient, $\lambda$ is the insolation in $(\mathrm{MW} / \mathrm{cm})$, and $I_{o}$ is the saturation current in diode reverse-biased direction.

The panel IV and PV characteristics curves are obtained by plotting the PV current and PV power as a function of the PV voltage as shown in Fig. 2. This figure illustrates also the location of three important points on the PV panel characteristics: the short-circuit current $I_{s c}$, the open-circuit voltage $V_{o c}$, and the maximum power point $V_{M P P}, I_{M P P}, P_{M P P}$.

\section{B. Power Converter Model}

The developed standalone PV system uses a buck converter as a power-processing unit. The buck converter circuit consists of a MOSFET switch and a freewheeling diode, in addition to a rectifier circuit based on a capacitor and an inductor as shown in Fig. 3. The circuit is controlled through a PWM signal generated by the MPPT controller.

The state-space averaging technique is used to generate the low-frequency small-signal ac equations of the PWM DC-DC converter [13]. The buck converter is assumed to operate in a continuous conduction mode while switching between two states depending on the switch position (ON/OFF). In the first state, $\left(0 \leq t \leq t_{\text {on }}\right)$, the switch will be $\mathrm{ON}$, and in the second state, $\left(\mathrm{t}_{\mathrm{on}} \leq \mathrm{t} \leq \mathrm{T}\right)$, the switch will be OFF. 


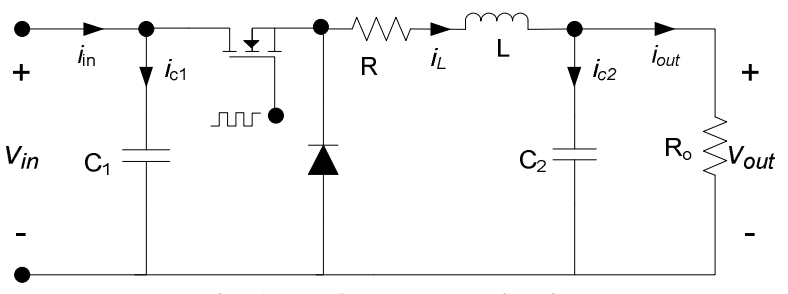

Fig. 3. Buck converter circuit

Taking the inductor current $i_{L}$, output voltage $v_{\text {out }}$, and input voltage $v_{i n}$ as state variables, the converter equations can be derived and written in state-space form for each switch state using $u=i_{i n}$ as the system input, $y=v_{i n}$ as the system output, and $x=\left[\begin{array}{lll}i_{L} & v_{\text {out }} & v_{\text {in }}\end{array}\right]^{t}$ as the state vector.

The duty cycle $d(t)=\frac{t_{o n}(t)}{T}$ is considered to be a timevarying quantity. It is assumed that the natural frequencies of the converter network are much smaller than the switching frequency. The converter waveforms are expressed as quiescent values plus small ac variations as follows [13]:

$$
\begin{aligned}
& x(t)=X+\hat{x}(t) \\
& u(t)=U+\hat{u}(t) \\
& y(t)=Y+\hat{y}(t) \\
& d(t)=D+\hat{d}(t)
\end{aligned}
$$

The small-signal ac model is then obtained as

$$
\left\{\begin{array}{l}
\frac{d \hat{x}(t)}{d t}=A \hat{x}(t)+B \hat{u}(t)+M \hat{d}(t) \\
\hat{y}(t)=E \hat{x}(t)+F \hat{u}(t)+H \hat{d}(t)
\end{array}\right.
$$

where

$$
\begin{aligned}
A & =\left[\begin{array}{ccc}
-\frac{R}{L} & -\frac{1}{L} & \frac{D}{L} \\
\frac{1}{C_{2}} & -\frac{1}{R_{o} C_{2}} & 0 \\
-\frac{D}{C_{1}} & 0 & 0
\end{array}\right], B=\left[\begin{array}{l}
0 \\
0 \\
\frac{1}{C_{1}}
\end{array}\right], \\
M & =\left[\begin{array}{cc}
\frac{D V_{i n}}{L} \\
0 \\
-\frac{D I_{L}}{C_{1}}
\end{array}\right], E=\left[\begin{array}{lll}
0 & 0 & 1
\end{array}\right], F=0, H=0 .
\end{aligned}
$$

The state-space averaged model that describes the quiescent converter waveforms is

$$
\left\{\begin{array}{l}
0=A X+B U \\
Y=E X+F U
\end{array}\right.
$$

The steady-state solution of the converter is therefore

$$
G_{\text {in }}=\frac{V_{\text {in }}}{I_{\text {in }}}=E(-A)^{-1} B+F
$$

This equation yields:

$$
G_{\text {in }}=\frac{R+R_{o}}{D^{2}}
$$

Equation (9) represents the DC equivalent input impedance of the buck converter [4]. Referring back to the small signal model (6), the control to PV voltage transfer function can be obtained as

$$
G_{c}(s)=\frac{\hat{v}_{\text {in }}(s)}{\hat{d}(s)}=-\left(\frac{b_{2} s^{2}+b_{1} s+b_{0}}{s^{3}+a_{2} s^{2}+a_{1} s+a_{0}}\right)
$$

where,

$$
\begin{aligned}
& b_{0}=\frac{D I_{L}}{L C_{1} C_{2}}+\frac{\left(D^{2} V_{i n}+D I_{L} R\right)}{R_{o} L C_{1} C_{2}}, \\
& b_{1}=\frac{1}{C_{1}}\left(\frac{D^{2} V_{i n}}{L}+\frac{D I_{L} R}{L}+\frac{D I_{L}}{R_{o} C_{1} C_{2}}\right), \\
& b_{2}=\frac{D I_{L}}{C_{1}} \\
& a_{0}=\frac{D^{2}}{L R_{0} C_{1} C_{2}}, \\
& a_{1}=\frac{R_{1}}{L R_{o} C_{2}}+\frac{1}{L C_{2}}+\frac{D^{2}}{L C_{1}}, a_{2}=\frac{1}{R_{o} C_{2}}+\frac{R}{L}
\end{aligned}
$$

\section{Proposed System Design}

Figure 4 shows the overall system architecture. The proposed MPPT controller builds upon the simplicity of the $\mathrm{P} \& \mathrm{O}$ technique but eliminates the resulting steady state oscillations by adaptively modifying the reference voltage perturbation step-size $\mathrm{C}$ using a fuzzy logic controller.

The operation of the $\mathrm{P} \& \mathrm{O}$ technique is explained by the flowcharts given in Fig. 5. The proposed control scheme takes the absolute power slope $S_{a}$ of the PV panel curve and the old voltage perturbation step $\mathrm{C}_{\text {old }}$ as its inputs and calculates the change in the new P\&O step size $\Delta C$. The two inputs will be fuzzified by using normalized fuzzy sets with three triangular membership functions (MFs): Small, Medium, and Large as shown in Fig. 6. The output variable consists of a normalized fuzzy set with triangular MF: Negative Big (NB), Negative Small (NS), Zero (ZO), Positive Small (PS), and Positive Big (PB) as shown in Fig. 7. 


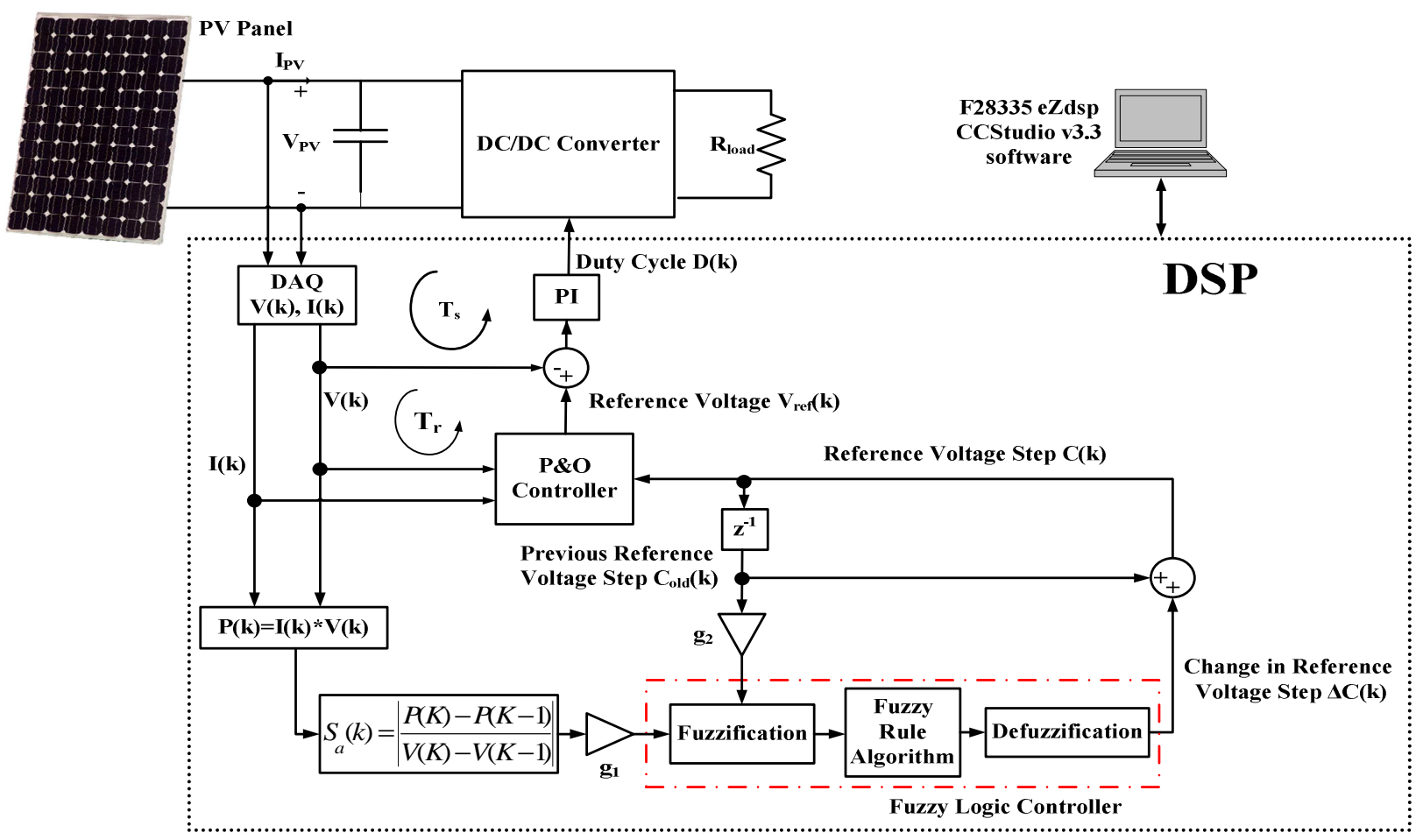

Fig. 4. The proposed DSP based standalone solar energy system

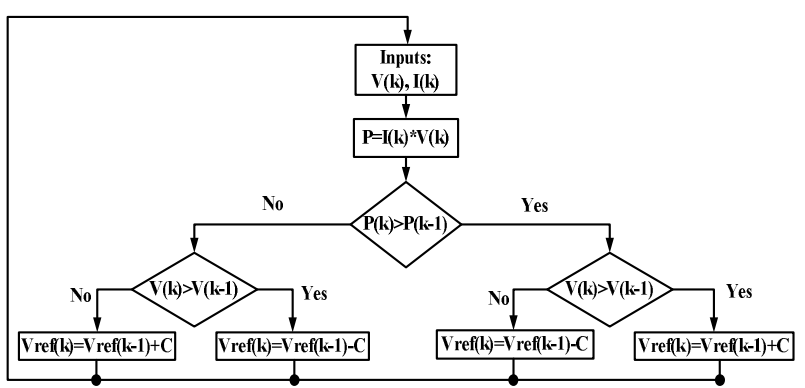

Fig. 5. P\&O method flow chart

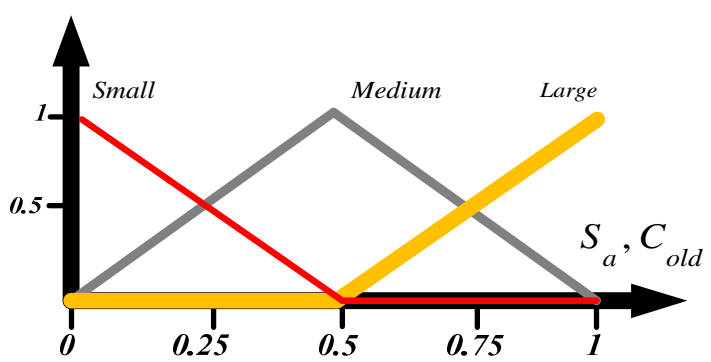

Fig. 6. MF of the two inputs $S_{a}$ and $C_{\text {old }}$

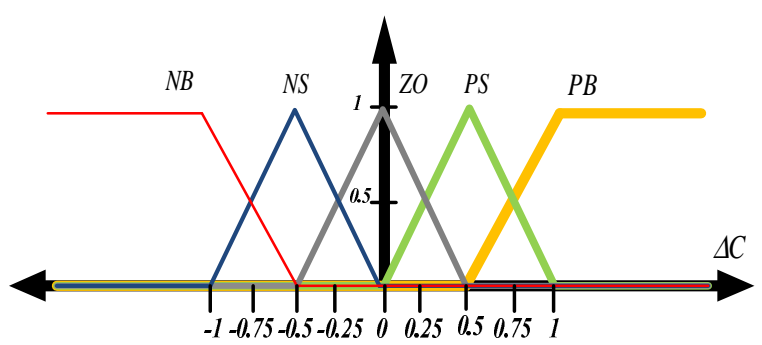

Fig. 7. MF of the output $\Delta \mathrm{C}$

\begin{tabular}{|c|c|c|c|}
\hline $\mathrm{S}_{\mathrm{a}}=\mathrm{dP} / \mathrm{dV} \mid$ & Small & Medium & Large \\
\hline Small & $\mathrm{ZO}$ & NS & NB \\
\hline Medium & PS & $\mathrm{ZO}$ & NS \\
\hline Large & PB & PS & $\mathrm{ZO}$ \\
\hline
\end{tabular}

After the fuzzification of the crisp inputs, the resulting fuzzy sets have to be compared to the rule-base. The rule base is a set of "If premise Then consequent" rules constructed according to the designer system knowledge and experience. Depending on the value of the absolute power slope, the PV panel curve (Fig. 2) can be divided into three regions. Given the old reference voltage and perturbation step $\mathrm{C}_{\text {old }}$, the controller will determine the change to the new step in order to reach the MPP.

Referring to Fig. 2, if the absolute value of the slope $S_{a}$ is Large, this means that the operating point is far from the MPP. The old step $\mathrm{C}_{\text {old }}$ can have in this case three different values. If $\mathrm{C}_{\text {old }}$ is Small, then the change in step size $\Delta \mathrm{C}$ has to be Positive $\mathrm{Big}(\mathrm{PB})$ in order to rapidly reach the MPP. Whereas if $\mathrm{C}_{\text {old }}$ is Medium, the change in step size $\Delta \mathrm{C}$ has to be Positive Small (PS) in order to reach the MPP without oscillating around it. Finally if $\mathrm{C}_{\text {old }}$ is Large, the change in step size $\Delta \mathrm{C}$ has to be Zero (ZO) in order to avoid exceeding the MPP in the opposite direction leading to oscillations. The same scenarios can be applied to the other cases resulting in the rule base shown in Table I. The premise, which is the first part of the rule, is calculated using the inference minimum operator. The operator compares between the rules that are $\mathrm{ON}$ in each input $\mathrm{MF}$ and takes the minimum rule. 
The last step in the FLC process is the defuzzification, which takes the implied fuzzy set and transforms it back to a real continuous number or a crisp output. The center of gravity (COG) defuzzification method is used in this work [14].

\section{Experimental Results \& Verification}

The performance of the inner MPPT voltage control loop is verified using step changes to the voltage reference. For the system under consideration, the PI controller gains were optimized as $K_{p}=0.01, K_{i}=0.05$ to yield a settling time $t_{s}=4.8 \mathrm{~s}$. A sampling interval $T_{r}=15 \mathrm{~s}$ is used in order to give the PV voltage enough time to reach the reference value before the next perturbation step. The parameters of the Isofoton 150 Watt PV panel and the buck converter are shown in Table II and Table III.

In order to analyze the MPPT system operation, two tests were performed. In both tests, the panel was fixed facing true south with a tilt angle of 52 degrees, which is the winter optimum angle for the city of Sharjah. In test 1 the conventional P\&O-MPPT was applied with a fixed reference step $\Delta \mathrm{V}_{\text {ref }}=0.8 \mathrm{~V}$. In test 2 , the FLC based P\&O-MPPT was used. The results are shown in Fig. 8.
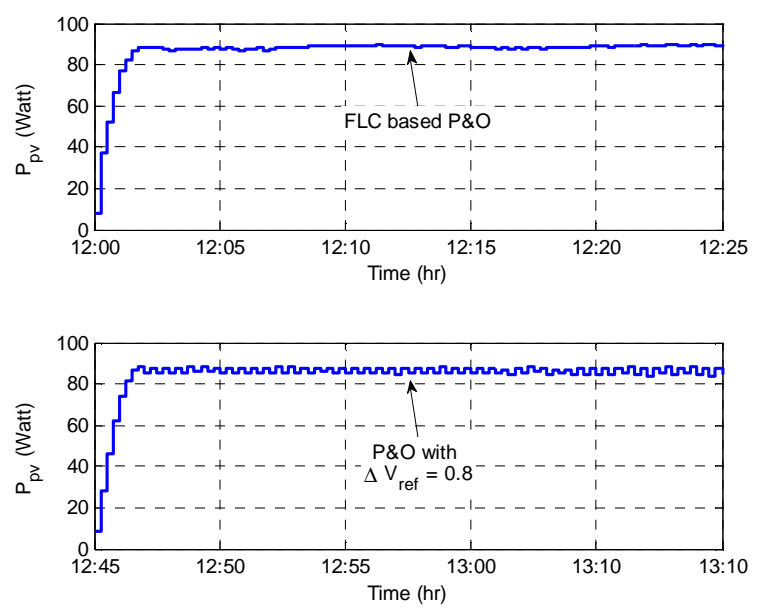

Fig. 8. PV power output on Nov. 21, 2011, FLC based (12:00-12:25), $\mathrm{P} \& \mathrm{O}$ with $\Delta \mathrm{V}_{\text {ref }}=0.8 \mathrm{~V}(12: 45-13: 10)$
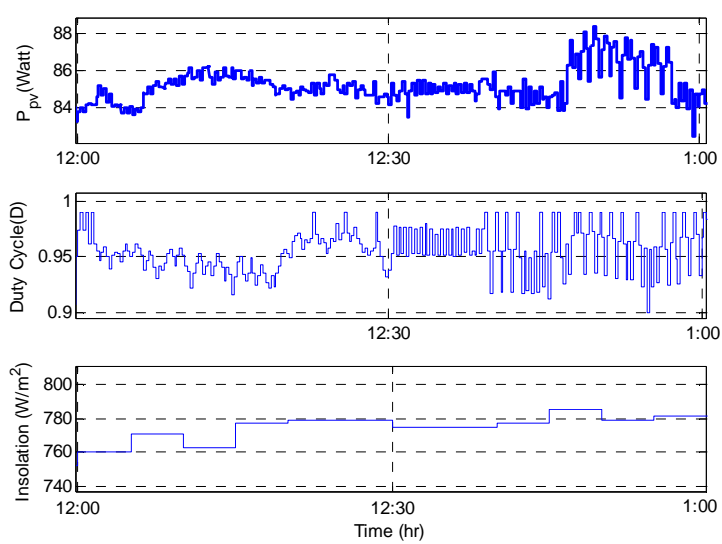

Fig. 9. Comparison between FLC based $\mathrm{P} \& \mathrm{O}$ and conventional P\&O (Jan. 1, 2012, 12:00 to 13:00)
Table II: PV panel parameters

\begin{tabular}{|c|c|c|c|c|}
\hline $\mathrm{P}_{\max }$ & $\mathrm{V}_{\max }$ & $\mathrm{I}_{\max }$ & $\mathrm{V}_{\mathrm{OC}}$ & $\mathrm{I}_{\mathrm{SC}}$ \\
\hline $150 \mathrm{~W}$ & $17.3 \mathrm{~V}$ & $8.7 \mathrm{~A}$ & $21.6 \mathrm{~V}$ & $9.3 \mathrm{~A}$ \\
\hline
\end{tabular}

Table III: Buck converter parameters

\begin{tabular}{|c|c|c|c|c|}
\hline $\mathrm{L}$ & $\mathrm{R}$ & $\mathrm{C}_{1}$ & $\mathrm{C}_{2}$ & $\mathrm{R}_{\mathrm{o}}$ \\
\hline $330 \mathrm{mH}$ & $0.074 \Omega$ & $470 \mu \mathrm{F}$ & $330 \mu \mathrm{F}$ & $1.6 \Omega$ \\
\hline
\end{tabular}

The FLC based MPPT results show that the maximum power is reached within a short time (5 samples) and the oscillations around the MPP are minimal. On the other hand, for the conventional $\mathrm{P} \& \mathrm{O}$ with $\Delta \mathrm{V}_{\text {ref }}=0.8 \mathrm{~V}$, the response was slower as it reached the MPP within 6 samples and kept oscillating around it.

Figure 8 shows the power output curve of the P\&O-MPPT compared to the Fuzzy-MPPT. This figure highlights clearly the features of the proposed fuzzy based MPPT, which improves the efficiency of the system by yielding higher power while eliminating the steady state oscillations around the MPP. The results show an enhancement of $2.53 \%$ in energy yielded by the proposed FLC based $\mathrm{P} \& \mathrm{O}$ controller compared to the conventional one when the panel is fixed.

Additional comparative analysis of the proposed FLC based system with the conventional $\mathrm{P} \& \mathrm{O}$ with $\Delta \mathrm{V}_{\text {ref }}=0.8 \mathrm{~V}$ is carried out over a full day testing. The two controllers were alternated every thirty minutes to check the transient and steady state performance. Figure 9 zooms at noontime for one-hour period with peak sun insolation. The results show that the PV power and duty cycle curves have more oscillations in steady state after 12:30 pm under the conventional $\mathrm{P} \& \mathrm{O}$.

In order to check the stability of the FLC-MPPT algorithm, the system inputs and outputs are plotted for one hour of testing. As shown in Fig. 10, the duty cycle reaches the MPP and keeps operating around it while the FLC system output converges to zero. Moreover, Fig. 10 shows the ability of the system to act against disturbances as it goes back to the steady state once the disturbances are cleared. Plotting the absolute value of the FLC output as a function of the two FLC inputs in a 3D plot shows that the system output converges to zero in steady state as shown in Fig. 11.

\section{Conclusion}

This paper presents a new adaptive P\&O MPPT technique using fuzzy logic control (FLC). The proposed control scheme takes the power slope of the PV panel curve and the old voltage perturbation step as its inputs and computes the optimal $\mathrm{P} \& \mathrm{O}$ voltage step size to reach the MPP without steady state oscillations. The controller was implemented on a 150-Watt prototype PV system. Experimental results obtained from outdoor testing show clearly the performance of the FLC based MPPT and its advantages compared to the conventional $\mathrm{P} \& \mathrm{O}$ technique. 

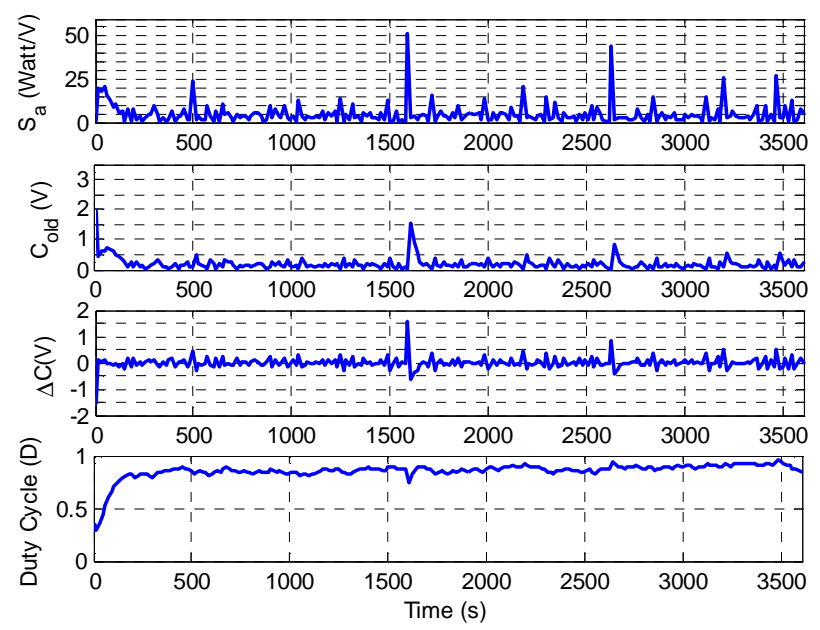

Fig. 10. FLC inputs and output for a sunny day with shading disturbances

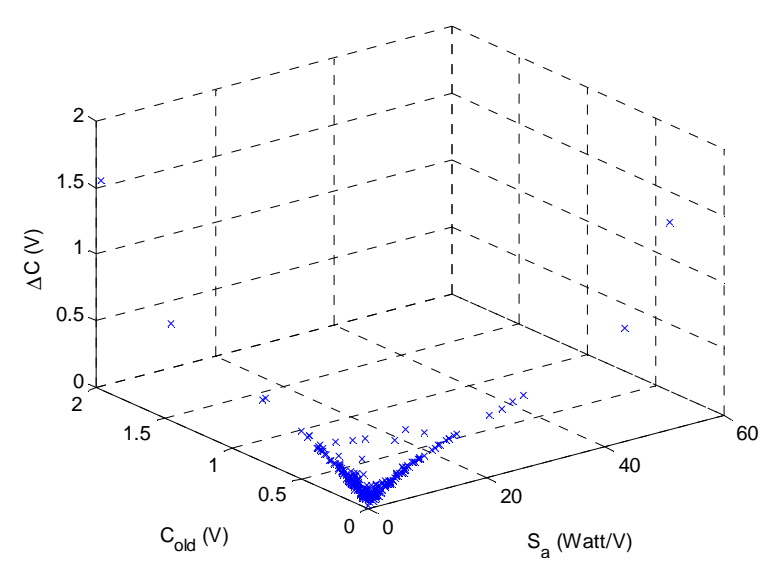

Fig. 11. FLC input/output mapping

\section{References}

[1] Fairley and P., "Fukushima's positive impact [Spectral Lines]," Spectrum, IEEE, vol. 48, no. 5, p. 8, May 2011.

[2] G. Spagnuolo et al., "Renewable energy operation and conversion schemes," IEEE Ind. Electron. Mag. , vol. 4, no. 1, pp. 38-51, Mar. 2010.

[3] D. Sonnenenergie, "Photovoltaic Basics," in Planning and installing photovoltaic systems: A guide for installers, architects, and engineers, 2nd ed., Deutsche Gesellschaft für Sonnenenergie, Ed. London: Earthscan Publications Ltd., 2008, ch. 1, pp. 1-62.

[4] E. Aranda, J.Gala' N, M. Cardona, and J.Rquez, "Measuring the I-V curve of PV generators," IEEE Ind. Electron. Mag., vol. 3, no. 3, pp. 4-14, September 2009.

[5] D. Hohm and M. Ropp, "Comparative study of maximum power point tracking algorithms," Progress In Photovoltaics: Research And Applications, vol. 11, pp. 4762,2003
[6] I. Houssamo, F. Locment, and M. Sechilariu, "Maximum power tracking for photovoltaic power system: Development and experimental comparison of two algorithms," Renewable Energy, vol. 35, pp. 2381-2387, 2010.

[7] J. Jiang, T. Huang, Y.Hsiao, and C.Chen, "Maximum power tracking for photovoltaic power systems," Tamkang Journal of Science and Engineering, vol. 8, no. 2, pp. 147153, Mar. 2005.

[8] C. Ahn, J. Choi, and D. Lee, "Adaptive maximum power point tracking algorithm for photovolatic power systems," IEICE Trans. Commun., vol. E93-B, no. 5, pp. 1334-1337, May 2010.

[9] A Safari and S. Mekhilef, "Simulation and hardware implementation of incremental conductance MPPT with direct control method using cuk converter," IEEE Trans. Ind. Electron., vol. 58, no. 4, pp. 1154-1161, Apr. 2011.

[10] C. Salah and M. Ouali, "Comparison of fuzzy logic and neural network in maximum power point tracker for PV systems," Electric Power Systems Research, vol. 81, pp. 43-50, 2011.

[11] S. Lalouni, D. Rekioua, T. Rekioua, and E. Matagne, "Fuzzy logic control of stand-alone photovoltaic system with battery storage," Journal of Power Sources, vol. 193, no. 5, pp. 899-907, Sep. 2009.

[12] G. Walker, "Evaluating MPPT converter topologies using a MATLAB PV model," J. Electr. Electron. Eng., vol. 21, no. 1, pp. 49-56, 2001.

[13] R. Erickson and D. Maksimović, Fundamental of Power Electronics, 2nd ed. Norwell, MA: Kluwer Academic Publishers, 2001.

[14] K. Passino and S. Yurkovich, Fuzzy Control. CA, USA: Addison Wesley Longman, Inc., 1998. 